\title{
Implementation of Incremental Conductance Method with Direct Control
}

\author{
A Safari \\ Department of Electrical Engineering \\ University Of Malaya, Kuala Lumpur, Malaysia \\ azadehsafari2008@gmail.com
}

\author{
S. Mekhilef \\ Department of Electrical Engineering \\ University Of Malaya, Kuala Lumpur, Malaysia \\ saad@um.edu.my
}

\begin{abstract}
This paper presents incremental conductance (IncCond) MPPT using direct control method in which duty cycle is adjusted inside the algorithm thus need for use another control loop is eliminated while tracking is done perfectly. The steady state oscillations are reduced and dynamic performance is improved. Design and theoretical study and analysis of the proposed system are provided and its feasibility is investigated in Matlab/ Simulink simulations. Eventually results are submitted to evaluate the closed loop system.
\end{abstract}

Keywords - Photovoltaic system; Maximum power point tracking; IncCond method; Direct control method.

\section{INTRODUCTION}

Since utilization of photovoltaic systems commercially to generate electricity, there has been lack of satisfying efficiency as the most significant dilemma. To overcome this problem some physical and electrical strategies have been invented. Because physical methods require additional hardware and equipment, electrical methods fascinated more attention and interest. Maximum power point tracking is an electrical method created for the purpose of achieving best efficiency and helps a PV system to always operate on the MPP at any operating condition. In other words, maximum power point trackers follow the MPPs using electrical rules and conditions to minimize the risk of power system failures exist due to a variety of ambient conditions. MPPT methods should be implemented to cope with the atmosphere conditions and extract the maximum power from the solar array.

In the last few years using maximum power point trackers are going to be very trendy in every PV system. It is almost essential in some categories of PV systems such as standalone systems to extract the most available power of the PV modules; thus searching about the maximum power produced by these systems is really vital.

Realizing the necessity of MPPTs, there have been dozens of different techniques proposed and still new articles and conferences are introducing new methods over and over again. Among all these methods some of them show excellent performance where the insolation and temperature are changing continuously [1-6].
Conventional incremental conductance method faced some alternatives on various aspects as well; such as fixed step size or variable step size. In the variable step size [8-12] verification, the efficiency is increased only $1 \%$ while the complexity of calculating new parameters such as "scaling factor" and step size is arduous and challenging. It requires calculating and setting the new factors for every PV system separately and follows tiresome rules.

Also some verification has been made in the fundamental principles of control circuit to improve the performance of the algorithm [13]. All these methods had affected the efficiency, speed and accuracy of the whole system but consecutively the cost and particularly the complexity of the system had been increased remarkably [1], [8-16].

Another evidence that shows the importance of simplicity of a system is that methods which were more uncomplicated and easy to implement such as $\mathrm{P} \& \mathrm{O}$ or hill climbing [17] draw more attention and used in other topics. Unfortunately, along with simplicity of these methods, there are excessive oscillations when they reach to the MPP results in high power losses. Hence employing a more accurate and efficient method that is also simple and easy to implement is a concern.

Searching in the offered methods, rarely can find a system that focuses on reducing the complexity while the efficiency improved or at least maintained.

Incremental conductance method is the algorithm that exhibits better performance than other techniques [5], [6], [13], [15]. It is more efficient, accurate, rapid and low cost technique without need for complicated mathematical operations and is independent of device physics. This control scheme can easily implemented using low cost microcontrollers and writing the program needs just a little literacy in $\mathrm{C}$ language and familiarity with programming.

In this paper, Incremental conductance with fixed step size is simulated. The main concern is to make design easier and straightforward on the whole system and evaluate tracking accuracy, steady state oscillations and efficiency. 


\section{INCREMENTAL CONDUCTANCE ALGORITHM}

This method is based on the fact that slop of the PV array power curve is zero at the MPP, increasing on the left of the MPP and decreasing on the right hand side of MPP. This can be express as follows:

$$
\begin{aligned}
& \frac{d P}{d v}=0 \\
& \frac{d P}{d V}>0 \\
& \frac{d P}{d V}<0
\end{aligned}
$$

\section{At MPP}

Left of MPP

Right of MPP

The flowchart of the fixed step IncCond MPPT is shown in Fig.1.

The algorithm starts by obtaining present values of $I(k)$ and $V(k)$ and using former values stored at the end of the preceding cycle, $I(k-1)$ and $V(k-1)$, then judge whether the voltage variable is zero, if it was zero then judge whether the current variable equals zero. Then if the current variable is also zero, it means that $\mathrm{PV}$ is operating on the MPP so the conductance should remain same and the current instruction does not need to change [8].

Two other checks are included to detect whether a control action is required when the array was not operating at the MPP; in this case the change in the atmospheric conditions is detected using $(d I \neq 0)$. Now the control signal adjustment will depend on whether $d I$ is positive or negative, if the incremental change in current is positive, the voltage instruction should be increased, otherwise be decreased.

On the other hand there is a condition where the voltage variable is not zero, thus another check is carried out by comparing $\frac{d I}{d V}$ with $-\frac{I}{V}$.

According to the result of this check; the control reference signal will be adjusted in order to move the array terminal voltage towards the MPP voltage. At the MPP, no control action is needed, therefore the adjustment stage will be bypassed and the algorithm will update the stored parameters at the end of the cycle as usual. If it was not true then if the conductance variable is more than the negative variable, the voltage instruction should be increased, otherwise be decreased.

\section{LOAD MATCHING}

When a PV module is connected to a load the operating point of the PV module will be at the intersection of the $I V$ curve and the load line.

Firstly, the PV module $I V$ curve is simulated and load matching will be discussed subsequently.

\section{A. PV Module IV Curve}

To draw $I V$ curve of a PV module, basic equations and characteristics of PV module is needed. PV output current equation shows that current and voltage of the PV module are non-linear and exponential. Here it's an equation for a module which is made up from solar cells [5]:

$$
I_{o}=n_{p} I_{p h}-n_{p} I_{r s}\left[\exp \left(k_{0} \frac{v}{n_{s}}\right)-1\right]
$$

Where:

$$
I_{p h}=\left[I_{s c r}+k_{i}\left(T-T_{r}\right)\right] \frac{s}{100}
$$

and

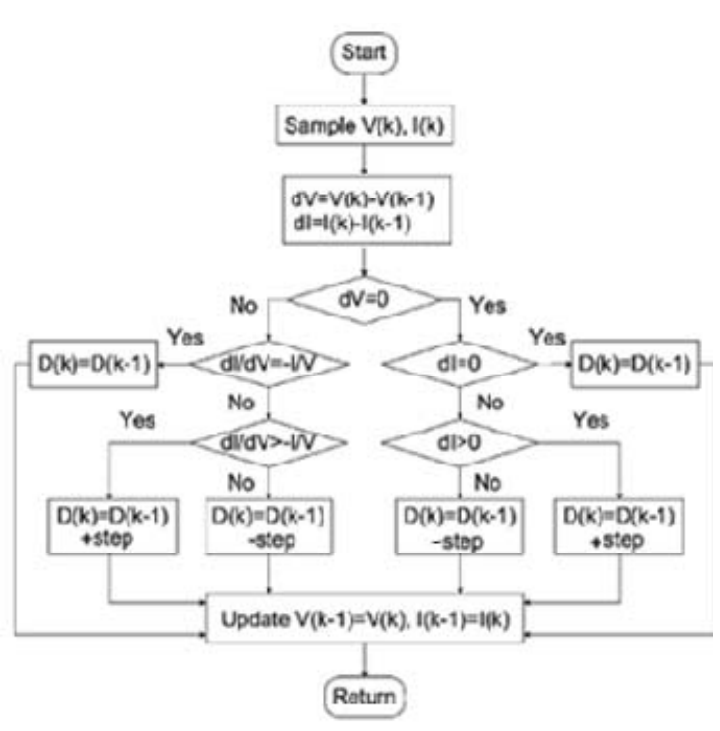

Fig.1. Incremental conductance algorithm

$$
I_{r s}=I_{r r}\left[\frac{T}{T_{r}}\right]^{3} \exp \left(\frac{q E_{G}}{k A}\left[\frac{1}{T_{r}}-\frac{1}{T}\right]\right) .
$$

The parameters are as follows:

$I_{o}$ is the PV array output current,

$V$ is the PV array output voltage,

Iph is the cell photocurrent that is proportional to solar irradiation,

Irs is the cell reverse saturation current that mainly depends on the temperature,

$K_{0}$ is a constant, calculating from: $k_{0}=\frac{q}{K T A}$ where $q$ is the charge of an electron, $\mathrm{k}$ is Boltzmann's constant, $\mathrm{T}$ is the cell temperature in Kelvin, $A$ is the $p-n$ junction ideality factor it ranges between 1 and 2 where 1 begin the ideal value.

$n_{s}$ and $n_{p}$ are respectively the number of series and parallel strings in the PV module

$I_{s c r}$ is the cell short-circuit current at reference temperature and radiation,

$k_{i}$ is short circuit current temperature coefficient,

$T_{r}$ is the cell reference temperature,

$S$ is solar irradiation in $\mathrm{mW/ \textrm {cm } ^ { 2 }}$.

$T_{r}$ is the cell reference temperature,

$I_{r r}$ is the reverse saturation at $T_{r}$,

$E_{G}$ is the band-gap energy of the semiconductor used in the cell [12].

KC85T module was chosen to be modeled and simulated. The electrical parameters are shown in table I.

TABLE I.

ELECTRICAL PARAMETERS OF THE KC85T MODULE FROM DATASHEET

\begin{tabular}{|c|c|c|}
\hline Electrical characteristics & & KC85T \\
\hline Maximum power & Pmax & $87 \mathrm{w}$ \\
\hline Voltage at MPP & Vmpp & $17.4 \mathrm{v}$ \\
\hline Current at MPP & Impp & $5.02 \mathrm{~A}$ \\
\hline Open circuit voltage & Voc & $21.7 \mathrm{v}$ \\
\hline Short circuit current & Isc & $5.34 \mathrm{~A}$ \\
\hline
\end{tabular}




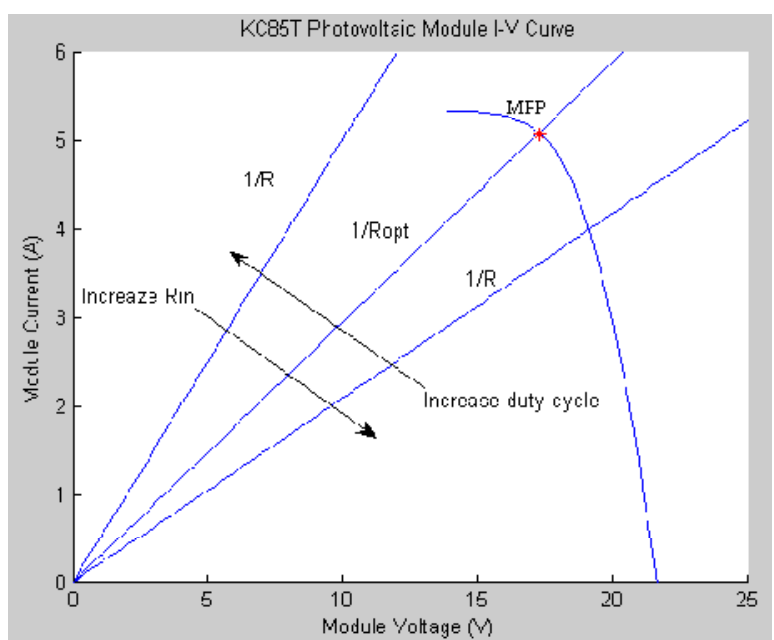

Fig.2. Impedance seen by PV is adjustable by duty cycle

Fig. 2, illustrates the $I V$ curve of the mentioned module. It shows that there could be many operating points on each $I V$ curve depending on the load. These points are located at the intersection of load and $I V$ curve; nevertheless there is unique impedance compatible with the MPP in that operating condition.

\section{B. Mechanism of Load Matching}

It is usually a DC-DC converter as the power stage conversion located between the PV module and load [14], [21], [22] to keep the operating point on the MPPs. By changing converter duty cycle the intersection point can move to the knee of the IV curve results in MPP.

The basic idea that makes switch mode power supply (SMPS) converters device of choice is the phenomenon so called "load matching". It refers to equalizing impedance of the load with the impedance seen by the PV module. Since SMPS converters exhibits good efficiency and their duty cycle is adjustable and adaptable, by setting the duty cycle mechanism of "load matching" can be reached (Fig. 3).

Following the load matching strategy, by equalizing the impedance of the load $\left(R_{\text {load }}\right)$ with the related impedance of the MPP $\left(R_{o p t}\right)$, maximum power can be exploited from the module.

$$
R_{\text {load }}=R_{\text {opt }}
$$

Where:

$$
\begin{aligned}
& R_{\text {load }}=\frac{V_{\text {out }}}{I_{\text {out }}} \\
& R_{\text {opt }}=\frac{V_{M P P}}{I_{M P P}}
\end{aligned}
$$

In the above equations, $V_{\text {out }}$ is the output voltage and $I_{\text {out }}$ is the output current of the converter. Similarly $V_{M P P}$ is the voltage and $I_{M P P}$ is the current at the MPP.

In reality similar impedances seldom occur, therefore presence of MPPT is strongly required. Cuk converter has been chosen. Mechanism of the load matching by this converter is described in following.

Output voltage of the cuk converter is given by:

$$
\frac{V_{o}}{V_{\text {in }}}=-\left(\frac{D}{1-D}\right)
$$

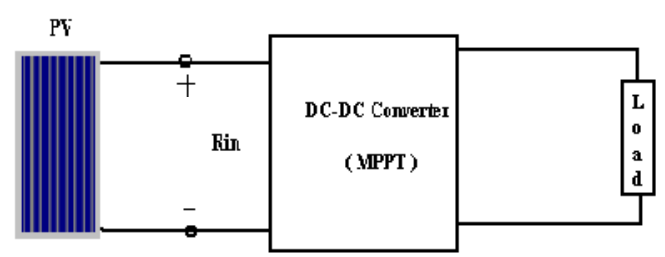

Fig.3. PV connected to the load via MPPT

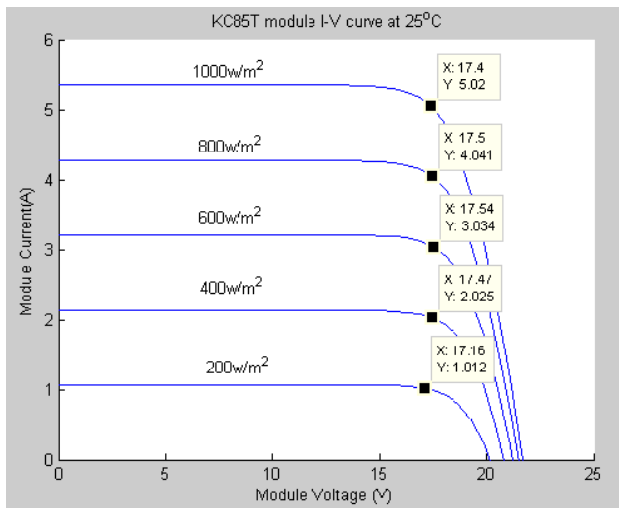

Fig. 4. KC85T module IV curve for different illumination levels

Assuming that this is an ideal and loss-less converter, the input power supplied by the source must be same as the output power absorbed by the load.

$$
\begin{aligned}
& P_{\text {in }}=P_{\text {out }} \\
& I_{\text {in }} \times V_{\text {in }}=I_{\text {out }} \times V_{\text {out }} \\
& V_{\text {in }}=-\left(\frac{1-D}{D}\right) V_{\text {out }} \\
& I_{\text {in }}=-\left(\frac{D}{1-D}\right) I_{\text {out }}
\end{aligned}
$$

So the input impedance of the Cuk converter can be calculated using (13) and (14):

$$
R_{\text {in }}=\frac{V_{\text {in }}}{I_{\text {in }}}=\frac{(1-D)^{2}}{D^{2}} \cdot R_{\text {load }}
$$

Last equation indicates that by changing duty cycle, the input impedance $\left(R_{\text {in }}\right)$ of converter should be equal to the optimum impedance ( $\left.R_{\text {opt }}\right)$ at which the system is working at MPP.

MPP methods generally use two common methods to measure the required parameter for controlling actions: input sensing and output sensing.

Using input sensing method, two sensors are required to measure the output current and voltage of PV module. Then algorithm will calculate the instantaneous and incremental conductance and determines the next step that PV module should operate on. This is done by changing duty cycle of the converter. Prior to set off trough the algorithm, there is a close look at how a converter is employed as MPPT. 
Using (13), (14) and (15) for Cuk converter yields:

$$
\begin{gathered}
D=\frac{1}{1+\sqrt{\frac{R_{\text {in }}}{R_{\text {load }}}}} \\
V_{\text {out }}=-\left(\frac{D}{1-D}\right) \cdot V_{\text {in }} \\
I_{\text {out }}=-\left(\frac{1-D}{D}\right) \cdot I_{\text {in }}
\end{gathered}
$$

Using (16), (17), (18) and data acquired from Fig.4, theoretical calculation was configured to determine the PV module output power for various illumination levels with MPPT (Table II).

The results are indicating that duty cycle is proportional to the output voltage and current of PV module which they are inherently pertaining to the solar irradiation. Thus, with more solar irradiation duty cycle will be increased to draw the maximum power available from the modules.

Another notable point is that by choosing proper load for the system, maximum power can be drawn from the modules. In other words if the load is incapable of absorb maximum power then some of the delivered power will be dissipated.

\section{SIMULATION}

Full simulation model of closed loop system is executed in Matlab/Simulink to investigate and distinguish the performance and functioning characteristics of the proposed system. One PV module with respect to its characteristics is modeled in Simulink as well. It takes the ambient temperature and solar irradiation and gives the current and voltage.

Cuk converter was chosen as the power interface stage since it has the merit of being capable to have both lower and higher output voltage. The components were selected as follows:

\section{$\mathrm{L} 1=\mathrm{L} 2=5 \mathrm{mH}$; \\ $\mathrm{C} 1=\mathrm{C} 2=47 \mu \mathrm{f}$; \\ Rload $=10 \Omega$;}

Switching frequency $=10 \mathrm{kHz}$.

Incremental conductance algorithm with direct control scheme was written in M-file in Matlab editor. With this configuration direct control method automatically adjusts the new duty cycle for the converter while reducing intricacy and complication of the system considerably.

The sampling time to update the values was chosen $0.1 \mathrm{~s}$. Simulations are performed to see the effect of varying irradiation and temperature is assumed fixed at $25^{\circ} \mathrm{C}$.

First irradiation is $1000 \mathrm{w} / \mathrm{m}^{2}$; at $\mathrm{t}=0.4 \mathrm{~s}$ illumination level suddenly changes to $400 \mathrm{w} / \mathrm{m}^{2}$ and then back to $1000 \mathrm{w} / \mathrm{m}^{2}$ at $\mathrm{t}=0.8 \mathrm{~s}$.

The results shows output power at $\mathrm{G}=1000 \mathrm{w} / \mathrm{m}^{2}$ and $400 \mathrm{w} / \mathrm{m}^{2}$ are $87 \mathrm{w}$ and $35 \mathrm{w}$ respectively which are absolutely the desired output power.
TABLE II.

UNREGULATED OUTPUT WITH RLOAD $=10 \Omega$ AT $25^{\circ} \mathrm{C}$

\begin{tabular}{|c|c|c|c|c|c|c|}
\hline Irradiation & $V_{M P P}(V)$ & $I_{M P P}(A)$ & $\mathrm{D}$ & $-V_{o}$ & $-I_{o}$ & $P_{\max }(w)$ \\
\hline 1000 & 17.4 & 5.02 & 0.63 & 29.62 & 2.96 & 87.67 \\
\hline 800 & 17.5 & 4.041 & 0.6 & 26.25 & 2.69 & 70.61 \\
\hline 600 & 17.54 & 3.034 & 0.56 & 22.32 & 2.38 & 53.1 \\
\hline 400 & 17.47 & 2.025 & 0.51 & 18.18 & 1.94 & 35.26 \\
\hline 200 & 17.16 & 1.012 & 0.43 & 12.94 & 1.34 & 17.33 \\
\hline
\end{tabular}

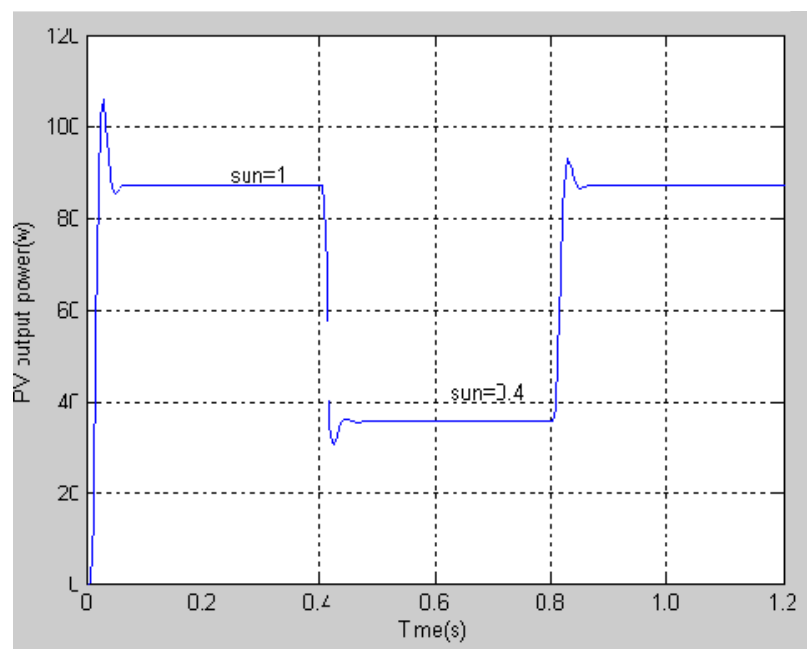

Fig.5. System response to changing irradiation

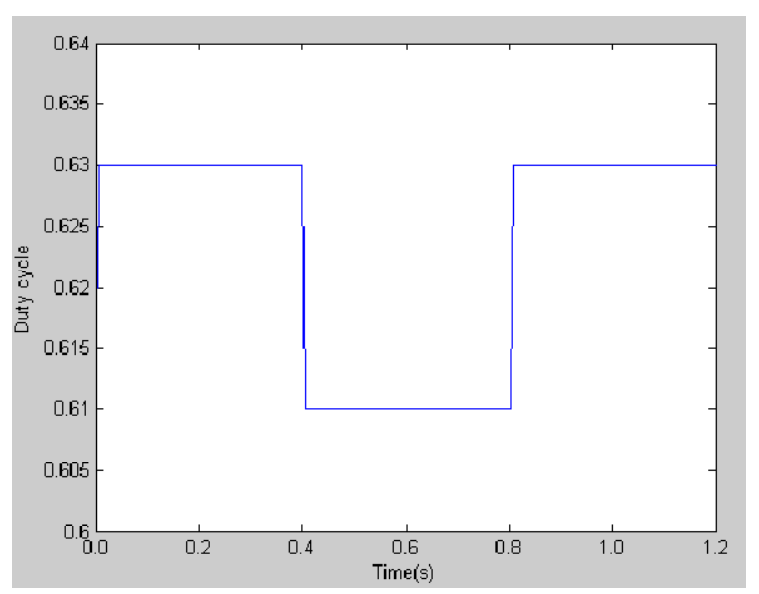

Fig.6. Change in duty cycle due to varying illumination level

Also Fig.6 shows change in duty cycle adjusted by MPPT to extract maximum power of the module. It shows that duty cycle is changing when illumination level changes and it decrease when illumination decrease.

\section{CONCLUSION}

In this paper, incremental conductance MPPT using direct control method has been presented, in which duty cycle is adjusted inside the algorithm thus need for use another control loop is eliminated. There is high tracking accuracy, no oscillations at steady state operation and 
ability to adapt with varying environmental conditions even if these changes happen very fast such as change in illumination level.

By choosing an appropriate step size properly there will be a tradeoff between steady state oscillations and dynamic performance of the system [5]. Results absolutely satisfy the suggestion in [23-24] to reach to the steady state condition in one cycle only.

\section{REFERENCES}

[1] R.Faranda, S.Leva and V.Maugeri, "MPPT techniques for PV systems: energetic and cost comparison," Electrical Engineering Department of Politecnico di Milano, Piazza Leonardo da Vinci. Milano, Italy. IEEE 2008.

[2] M. E. Ahmed, and S. Mekhilef, "Design and Implementation of a Multi Level Three-Phase Inverter with Less Switches and Low Output Voltage Distortion," Journal of Power Electronics, vol. 9, pp. 594-604, July 2009.

[3] S. Mekhilef, A. M. Omar, and N. A. Rahim, "Modeling of three-phase uniform symmetrical sampling digital PWM for power converter," IEEE Transactions on Industrial Electronics, vol. 54, pp .427-432, February 2007.

[4] S. Mekhilef, R. Saidur, and A. Safari, "A review on solar energy use in industries," Renewable and Sustainable Energy Reviews, Elsevier, vol. 15, pp. 1777-1790, May 2011 .

[5] K.H. Hussein, I. Muta, T.Hoshino, M. Osakada, "Maximum photovoltaic power tracking: an algorithm for rapidly changing atmospheric conditions," IEE Proc.Gener, transm. Distrib vol.142, NO.1, January 1995.pp.59 64.

[6] Trishan Esram, Patrick L. Chapman, "Comparison of photovoltaic array maximum power point tracking techniques," IEEE Transactions on Energy Conversion, vol. 22, NO. 2, pp.439 449 JUNE 2007.

[7] M. N. A. Kadir, S. Mekhilef, and H. W. Ping, "Voltage Vector Control of a Hybrid Three-Stage Eighteen-Level Inverter by Vector Decomposition," IET Transaction on Power Electronics, vol. 3, pp. 601- 611, July 2010.

[8] Zhou Yan, Liu Fei, Yin Jinjun, Duan Shanxu, "Study on realizing MPPT by improved incremental conductance method with variable step-size," IEEE 2008, pp. 547 550.

[9] Bangyin Liu, Shanxu Duan, Fei Liu, and Pengwei Xu, "Analysis and improvement of maximum power point tracking algorithm based on incremental conductance method for photovoltaic array," PEDS 2007, IEEE pp.637 641.

[10] S. Mekhilef, and M. N. Abdul Kadir," Voltage Control of Three-Stage Hybrid Multilevel Inverter Using Vector Transformation," IEEE Transactions on Power Electronics, vol. 25, pp. 2599- 2606, May 2010.

[11] T. S. Ustun, and S. Mekhilef, "Effects of a Static Synchronous Series Compensator (SSSC) Based on Soft Switching 48-Pulse PWM Inverter on the Power Demand from the Grid," Journal of Power Electronics, vol. 10, pp. 85-90, January 2010.

[12] Fangrui Liu, Shanxu Duan, Fei Liu, Bangyin Liu, and Yong Kang, "A Variable step size INC MPPT method for PV systems," IEEE transactions on industrial electronics, vol. 55, no. 7, July 2008, pp.2622 2628.

[13] Tae-Yeap Kim, Ho-Gyun Ahn, Seung-Kyu Park, Youn-Kyu Lee, "A novel maximum power point tracking control for photovoltaic power system under rapidly changing solar radiation," Ssangyong heavy Industries Co., Ltd. Department of Electrical engineering, Changwon National Univ.Korea.pp1011 1014.

[14] Chihchiang Hua and Chihming Shen, "Study of maximum power tracking techniques and control of $\mathrm{DC} / \mathrm{DC}$ converters for Photovoltaic Power System,” IEEE 1998, pp.86 93.

[15] Jae Ho Lee, HyunSu Bae and Bo Hyung Cho, "Advanced incremental conductance MPPT algorithm with a variable step size," Seoul National University, School of Electrical Engineerimg and computer science, Seoul, Korea.

[16] M.S. Aït Cheikh, C. Larbes†, G.F. Tchoketch Kebir and A. Zerguerras, "Maximum power point tracking using a fuzzy logic control scheme," IEEE, Revue des Energies Renouvelables vol. 10 NO.3, 2007, pp.387 395 .

[17] Wenkai Wu, N. Pongratananukul, Weihong. Qiu, K.Rustom, T. Kasparis and I. Bataresh " DSP-based multiple peak power tracking for expandable power system," Department of Electrical and Computer Engineering, College of Engineering and Computer Science, University of Central Florida, Orlando, Florida, Spring 2003.

[18] S. Mekhilef, and M. N. Abdul Kadir, "Novel Vector Control Method for Three-Stage Hybrid Cascaded Multilevel Inverter," IEEE Transactions on Industrial Electronics, vol. 58, pp. 1339-1349, April 2011.

[19] A. Safari, and S. Mekhilef, "Simulation and Hardware Implementation of Incremental Conductance MPPT with Direct Control Method Using Cuk Converter," IEEE Transactions on Industrial Electronics, vol. 58, pp. 1154 1161, April 2011.

[20] T. S. Ustun, and S. Mekhilef, “ Design and Implementation of Static Synchronous Series Compensator with a softswitching H-bridge Inverter with DSP-Based Synchronization Control," International Review of Electrical Engineering (IREEE), vol. 5, pp. 1347-1353, July- August 2010.

[21] Eftichios Koutroulis, Kostas Kalaitzakis, member, IEEE, And Nicholas C. Voulgaris, "Development of a microcontroller-based, photovoltaic maximum power point tracking control system," IEEE transactions on power electronics, vol. 16, NO. 1, January, 2001.

[22] Mr. R. B. Darla, "Development of maximum power point tracker for PV panels using SEPIC converter", India.2007.

[23] Mohamad N. Abdul Kadir, S. Mekhilef and H. W. Ping "Dual Vector Control Strategy for a Three-Stage Hybrid Cascaded Multilevel Inverter" Journal of Power Electronics, vol. 10, no. 2, pp.155-164, 2010

[24] N. Femia, G. Petrone, G. Spagnuolo, andM. Vitelli, "Optimization of perturb and observe maximum power point tracking method," IEEE Trans. Power Electron., vol. 20, no. 4, pp. 963-973, Jul. 2005. 